\title{
BIBECHANA
}

ISSN 2091-0762 (Print), 2382-5340 (Online)

Journal homepage: http://nepjol.info/index.php/BIBECHANA

Publisher: Department of Physics, Mahendra Morang A.M. Campus, TU, Biratnagar, Nepal

\section{Insight of precursor concentration, particle size and band gap of zirconia nanoparticles synthesized by co-precipitation method}

\author{
Arun Bhujel ${ }^{1}$, Bibek Sapkota ${ }^{1}$, Ram Lochan Aryal ${ }^{2}$, Bhoj Raj Poudel ${ }^{1}$, Sitaram Bhattarai ${ }^{1,3}$, \\ Surendra K. Gautam ${ }^{1, *}$ \\ ${ }^{1}$ Department of Chemistry, Tri-Chandra Campus, Tribhuvan University, Kathmandu, Nepal \\ ${ }^{2}$ Department of Chemistry, Amrit Campus, Tribhuvan University, Kathmandu, Nepal \\ ${ }^{3}$ Center for Nanomaterials, Sogang University, Seoul, South Korea \\ *Email:sgautam2055@yahoo.com
}

Article Information:

Received: May 14, 2020

Accepted: June 8, 2020

Keywords:

Zirconia

Monoclinic

Calcination

Raman spectra

Band gap

\begin{abstract}
Zirconia $\left(\mathrm{ZrO}_{2}\right)$, an inorganic material, is a very fascinating material due to its high mechanical strength and fracture toughness. The synthesis is carried out by using co-precipitation method using optimum content of zirconium oxychloride octahydrate $\left(\mathrm{ZrOCl}_{2} .8 \mathrm{H}_{2} \mathrm{O}\right)$ with $\mathrm{NaOH}$ solution at calcination temperature of $700^{\circ} \mathrm{C}$. The synthesized samples were characterized to ensure structural, functional, morphological and chemical composition by several techniques. The monoclinic structure has been confirmed from XRD, SAED and Raman spectra. The $\mathrm{Zr}-\mathrm{O}$ stretching vibration and $\mathrm{Zr}-\mathrm{O}_{2}-\mathrm{Zr}$ bending vibrations were confirmed through FTIR analysis. The well dispersed particles with spherical morphology were established through SEM and TEM analyses. EDX spectra confirmed the formation of pure zirconium oxide. The band gap was calculated with the help of UV-Vis spectra and particle size was determined form XRD data using Debye Scherrer's equation. The variation of band gap and particle size compared with different concentrations of precursor solution was studied.
\end{abstract}

DOI: https://doi.org/10.3126/bibechana.v18i1.28958

This work is licensed under the Creative Commons CC BY-NC License. https://creativecommons.org/licenses/by-nc/4.0/

\section{Introduction}

Nanomaterials are considered as intermediate between classical molecular scale and micron sized entities. The synthesis of nanomaterials with structural ability are great importance with unique physical and chemical properties in comparison with those bulk counterparts, and their properties based on quantum confinement effect and high surface area. Recently, many studies performed on the oxide material such as $\mathrm{TiO}_{2}, \mathrm{Al}_{2} \mathrm{O}_{3}, \mathrm{ZnO}_{2}, \mathrm{ZrO}_{2}$ etc., among those, zirconia is very fascinating material in current technology [1]. Among metal oxides, zirconia $\left(\mathrm{ZrO}_{2}\right)$ nanoparticles have been widely studied because of their high thermal and chemical stability, mechanical strength, chemical inertness and corrosion resistance as well as high 
water retention [2]. Zirconia is one of the important ceramics used as a biomaterial that has a bright future because of its distinctive characteristic called transforming toughening, which can give it higher strength and toughness compared to other ceramics. It has unique electrical, mechanical, optical and thermal properties, which make it a good choice for applications such as: structural materials, thermal barrier coatings, solid oxide fuel cell electrolytes, and semiconductor materials. Its stable photochemical properties make it directly applicable to photonics and can be used as catalyst in various reactions such as isomerization of alkanes, dehydration of alcohols, decomposition of nitrous oxide, etc. [3].

The zirconia nanoparticles can exist in a number of polymorphs at atmospheric pressure and are monoclinic (below $1170^{\circ} \mathrm{C}$ ), tetragonal (lie in the range of $1170^{\circ} \mathrm{C}-2370^{\circ} \mathrm{C}$ ) and cubic (above $2370^{\circ} \mathrm{C}$ ). The tetragonal phase of zirconia is considered to be highly catalytic with low thermal conductivity and thermal coefficient compared with others. Recently, a high-pressure allotropic form of zirconia (orthorhombic) has been reported, which is metastable at atmospheric pressure and reverts to the monoclinic phase [4].

Various methods of synthesis of $\mathrm{ZrO}_{2}$ have been established and inspected including sol-gel [5], combustion [6], sonochemical [7], hydrothermal [8] and co-precipitation method [9] etc. Among the various methods, co-precipitation method has been widely practiced as an efficient method for production of homogenous, high purity and crystalline oxide powders at low cost and simplicity of the method allows the mass production. Furthermore, the particle with preferred shape and size can be produced if solvent, $\mathrm{pH}$, solute concentration, reaction temperature, reaction time and the type of solvent conditions are optimized [10].

In this study, we report a simple and inexpensive synthesis route of pure and crystalline $\mathrm{ZrO}_{2}$ nanoparticles. Thus obtained samples are characterized using various microscopic and spectroscopic methods. The variation of band gap and particle size is accounted with various concentrations of precursor solutions. The work is limited in terms of theoretical interpretations and experimental supports for the transition of different forms of Bravais lattice upon temperature variation. This study is also bounded with $0.05 \mathrm{M}$ and $0.1 \mathrm{M}$ concentration of zirconium precursor solution to determine particle size and band gap energy.

\section{Materials and Method}

\section{Synthesis}

The synthesis approach is very simple and does not require any special set up. Zirconium oxide was prepared from the reaction between zirconium precursor solution i.e. Zirconium oxychloride octahydrate $\left(\mathrm{ZrOCl}_{2} .8 \mathrm{H}_{2} \mathrm{O}\right)$, which was obtained from LOBA Chemie Pvt. Ltd. and alkaline solutions of sodium hydroxide $(\mathrm{NaOH})$, ethanol and acetone were all obtained from Thermo-Fisher Scientific India Pvt. Ltd, Mumbai. All the reactants used were of analytical grades and were used without further purification. Distilled water was used throughout the experiments.

Appropriate amount of zirconium oxychloride octahydrate was dissolved in distilled water using hot plate magnetic stirrer to prepare its $0.05 \mathrm{M}$ and $0.1 \mathrm{M}$ solutions. Aqueous $\mathrm{NaOH}$ solution was mixed with above precursor solutions until the $\mathrm{pH}$ value became 8 . The precipitate thus obtained was filtered after 15 minutes, washed with water and acetone several times and finally was dried at $100^{\circ} \mathrm{C}$ overnight. The samples of $\mathrm{ZrO}_{2}$ were calcined at $700^{\circ} \mathrm{C}$ for 2 hours and were coded as $\mathrm{Z1}$ $(0.05 \mathrm{M})$ and Z2 (0.1M).

\section{Characterization}

The crystalline structure, phase composition and crystallite size of the powder samples obtained from above processes were analyzed from XRD patterns obtained using $\mathrm{Cu} k \alpha$ radiations $(\lambda=1.514$ $\AA$ ) for $2 \theta$ value ranging from $10^{\circ}$ to $90^{\circ}$ in X-Ray Diffractometer (Rigaku ultima IV model). The 
morphology of the samples was analyzed by Transmission Electron Microscopy (Technai G 20 Electron Microscope), Scanning Electron Microscopy (JEOL-JSM-7600F). FTIR (IRTracer100, SHIMADZU) spectra of the samples were employed to identify the chemical structure of the samples in a range of $4000-400 \mathrm{~cm}^{-1}$. The UV-Vis absorption spectra were obtained from UV-Vis spectrophotometer (ELICO SL 177). The presence of a monoclinic structure was studied through Raman spectroscopy (EnSpectra Professional v.1.6.0.1822) and their atomic weight percentage was identified via EDX (JEOL-JSM-6700F) analysis.

\section{Results and Discussion}

\section{XRD diffraction patterns}

Figures 1(a) and 1(b) show the XRD patterns of the as-prepared calcined samples of zirconia using $0.05 \mathrm{M} \mathrm{ZrOCl}_{2} .8 \mathrm{H}_{2} \mathrm{O}(\mathrm{Z} 1)$ and $0.1 \mathrm{M} \mathrm{ZrOCl}_{2} .8 \mathrm{H}_{2} \mathrm{O}$ (Z2) solutions, respectively and their corresponding Lorentzian fitting. The XRD patterns show that samples exist in crystalline state which is evident from the presence of distinct diffraction peaks. The peak at (1-11) orientation have high intensity than the other peaks, which was attributed to the high crystalline nature of the particular orientation of the samples. Lorentzian fitting was done for each sample to obtain FWHM value and the average grain size of the crystalline samples Z1 and Z2 are estimated as $28.3 \mathrm{~nm}$ and $33.3 \mathrm{~nm}$, respectively using Debye Scherrer's equation $[11,12]$, which are comparable with the previous studies [13-15]. As the concentration of the precursor solution increases from $0.05 \mathrm{M}$ to $0.1 \mathrm{M}$, the particle size also increased from $28.3 \mathrm{~nm}$ to $33.3 \mathrm{~nm}$.

From the diffraction patterns the peaks are indexed as monoclinic (baddeleyite) $\mathrm{ZrO}_{2}$ with lattice constants $\mathrm{a}=0.377 \mathrm{~nm}, \mathrm{~b}=0.447 \mathrm{~nm}, \mathrm{c}=0.476$ $\mathrm{nm}$ and $\alpha=\gamma=90^{\circ}$ and $\beta=80^{\circ}$, which are in good agreement with those of standard data (JCPDS card 37-1484) [16]. The bond length of the $\mathrm{Zr}-\mathrm{O}$ bond is found to be $1.88 \AA$ and bond angle of $\mathrm{O}-\mathrm{Zr}$-O was found to be $109.47^{0}$. The molecular coordination geometry of the baddeleyite form of monoclinic crystal structure of $\mathrm{ZrO}_{2}$ sample (with hkl=111) drawn from Avogadro's 1.2 version is shown in Figure 2.

\section{Fourier transform infrared spectroscopy Analysis}

The FTIR spectra obtained for as-prepared samples $\mathrm{Z} 1$ and $\mathrm{Z} 2$ are shown in Figure 3 where, broad absorption band particularly at about $700-750 \mathrm{~cm}^{-1}$ due to $\mathrm{Zr}-\mathrm{O}_{2}-\mathrm{Zr}$ asymmetric and about $400-500 \mathrm{~cm}^{-1}$ due to $\mathrm{Zr}-\mathrm{O}$ stretching modes confirm the formation of $\mathrm{ZrO}_{2}$ phases having monoclinic structure. The FTIR studies were in good agreement with the XRD pattern of the zirconia sample $[1,10]$. The extended spectrum in the region above $1000 \mathrm{~cm}^{-1}$ signifies the mesostructure having an amorphous surface of the sample with chemisorbed $\mathrm{H}_{2} \mathrm{O}$ molecules, which disappears at high temperature $[10,17]$.

\section{Scanning electron microscopic study}

Figure 4(a) displays the SEM micrograph and Figure 4(b) the corresponding histogram of $\mathrm{ZrO}_{2}$ sample (Z1). SEM image reveals that primary particles aggregate into secondary particles to form a cluster because of their small dimensions and high surface energy. The size of these nanomaterials is difficult to determine precisely by simple visual inspection due to agglomeration. Hence, ImageJ software was used on the SEM image to obtain the histogram as shown in Figure 4(b) and the average particle size was estimated to be $\sim 75 \mathrm{~nm}$ (from isolated regions with reasonable contrasts) which is bigger as compared to the size obtained from XRD data as $28-33 \mathrm{~nm}$. It is simply due to the agglomeration of the particles because of the high surface energy. This implies that the growth of the size of the nanoparticle is mostly considered to be the result of the surface aggregation of colloidal particles (cluster by cluster growth), although, the surface morphology shows that the nanoparticles formed are of crystallite structure. 


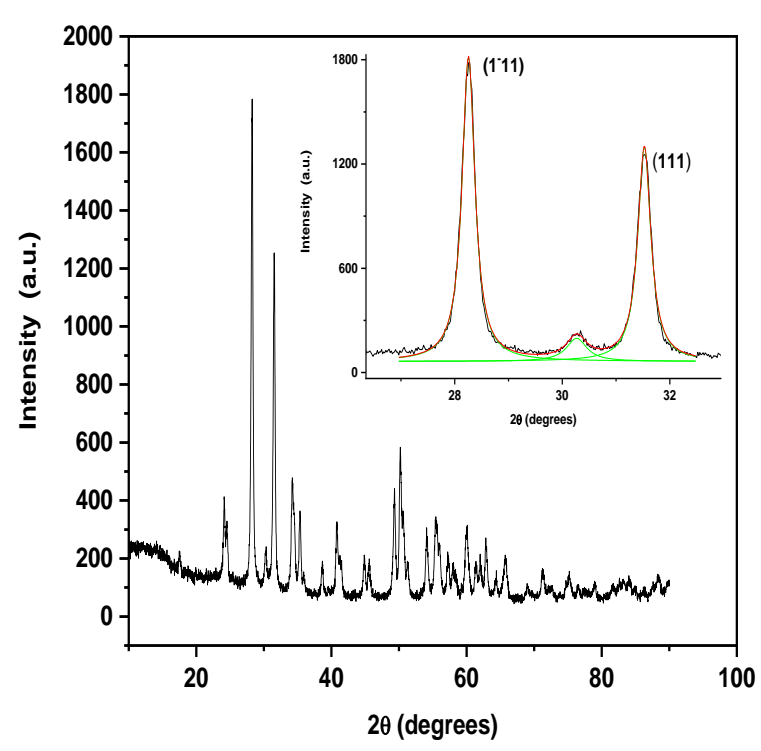

(a)

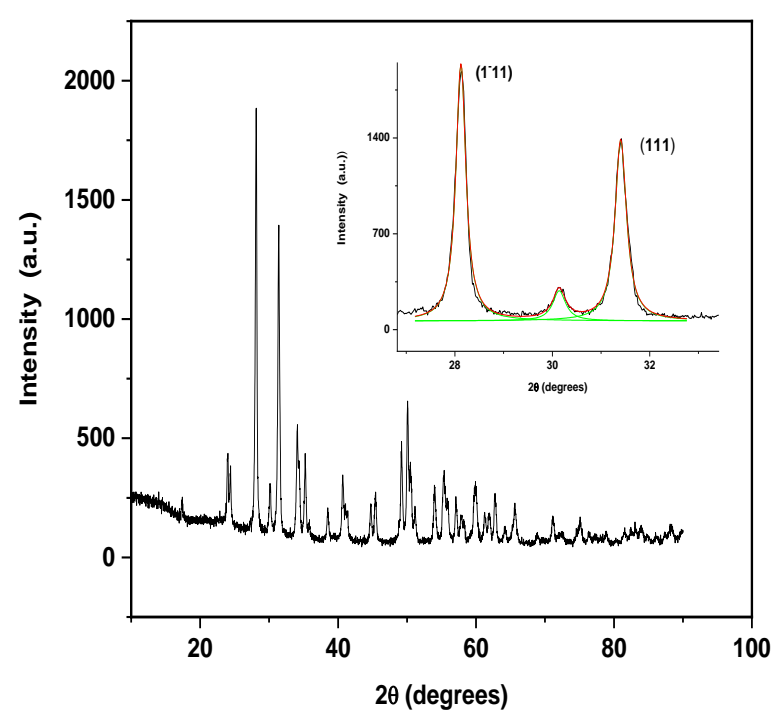

(b)

Fig. 1: XRD patterns of zirconia synthesized using (a) $0.05 \mathrm{M} \quad \mathrm{ZrOCl}_{2} .8 \mathrm{H}_{2} \mathrm{O} \quad(\mathrm{Z1})$ and (b) $0.1 \mathrm{M}$ $\mathrm{ZrOCl}_{2} .8 \mathrm{H}_{2} \mathrm{O}$ (Z2) and their corresponding Lorentzian fitting for FWHM calculation.

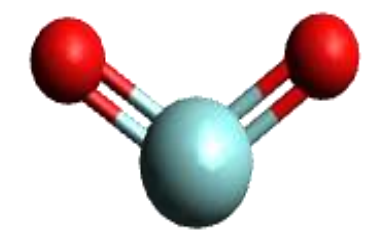

(a)

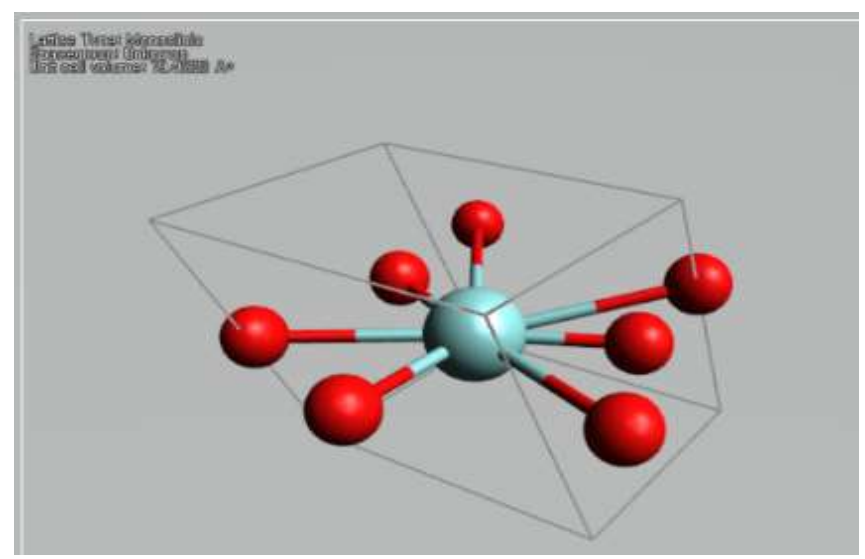

(b)

Fig. 2: (a) Molecular coordination geometry and (b) baddeleyite form of monoclinic crystal structure of $\mathrm{ZrO}_{2}$ with $(\mathrm{hkl}=111)$. (Drawn from Avogadro's 1.2 version).

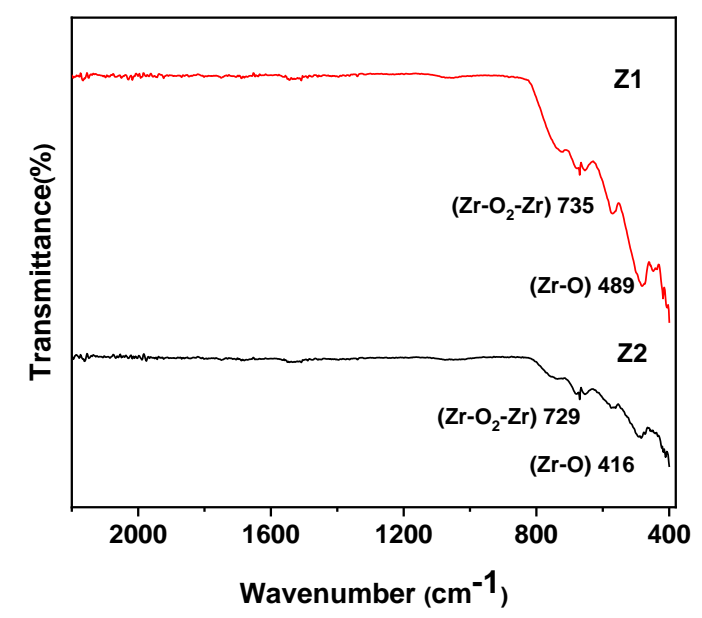

Fig. 3: FTIR spectra of Zirconia samples. 


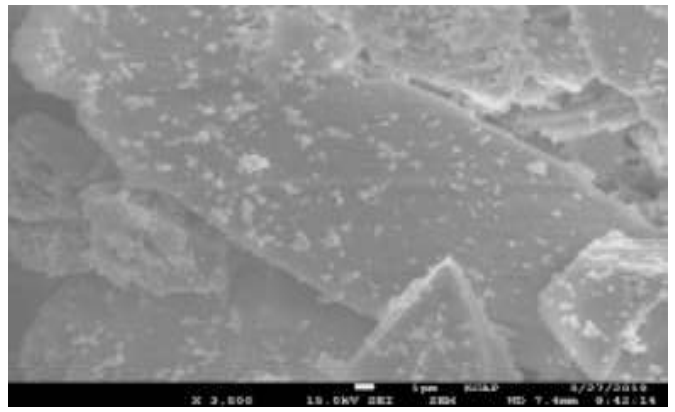

(a)

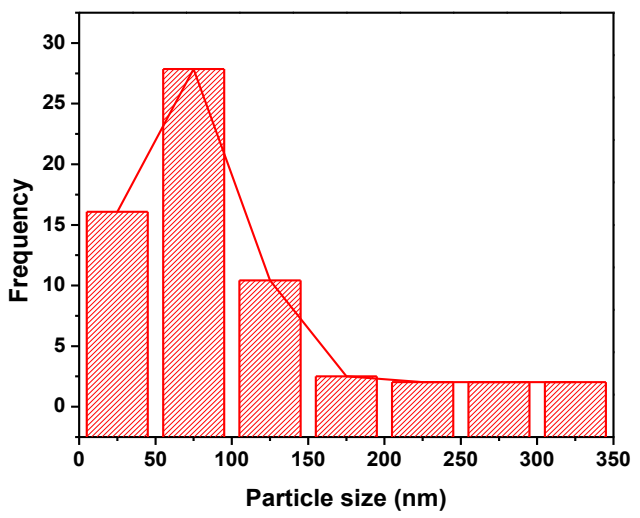

(b)

Fig. 4: (a) SEM image of zirconia prepared using $0.05 \mathrm{M} \mathrm{ZrOCl}_{2} .8 \mathrm{H}_{2} \mathrm{O}(\mathrm{Z1})$ and (b) its corresponding histogram, as obtained from ImageJ software.

Figure 5 reveals the EDX spectra of $\mathrm{ZrO}_{2}$ (sample $\mathrm{Z1)}$ with presence of $\mathrm{Zr}$ and $\mathrm{O}$ peaks which confirms the formation of pure zirconium oxide with no presence of impurities.

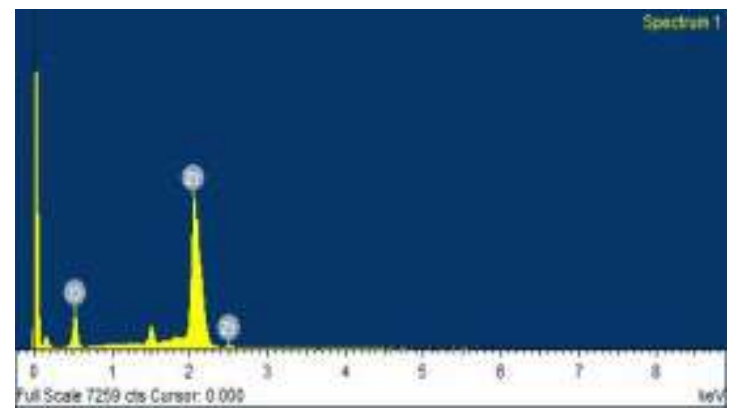

Fig. 5: EDX spectra of $\mathrm{ZrO}_{2}$ nanoparticle (Z1) synthesized from $0.05 \mathrm{M} \mathrm{ZrOCl}_{2} \cdot 8 \mathrm{H}_{2} \mathrm{O}$.
The average atomic percentage ratio of $\mathrm{Zr}: \mathrm{O}$ was found to be 26.95:73.05 for Z1 sample as shown in Table 1.

Table 1: EDX result showing the compositions of $\mathrm{ZrO}_{2}$ nanoparticle $(\mathrm{Z} 1)$

\begin{tabular}{|c|c|c|}
\hline Element & Weight \% & Atomic \% \\
\hline Oxygen & 32.33 & 73.05 \\
\hline Zirconium & 67.77 & 26.95 \\
\hline
\end{tabular}

\section{Transmission electron microscopic (TEM) study}

Figure 6 (a) depicts TEM image of the zirconia nanoparticle (Z1), which reveals that zirconia nanoparticles were almost agglomerated with a natural sensation because the surface forces such as van-der wall forces, capillary forces and electrostatic forces can be overwhelmed only against gravitational and inertial forces for particular size assortment. This image also revealed that small particles aggregate into secondary particles because of their small dimensions and high surface energy.

The average size of prepared nanoparticle was also calculated from TEM image by using ImageJ software and was found to be $\sim 80 \mathrm{~nm}$ which is nearly in agreement with the size obtained from SEM image. This was further clarified by the histogram and the Gaussian fitting spectra as shown in Figure 6(b).

The TEM-EDX pattern is shown in Figure 7(a), which also confirms the synthesis of pure $\mathrm{ZrO}_{2}$ due to presence of only corresponding zirconium and oxygen peaks. SAED pattern as illustrated in Figure 7(b) proves the characteristics diffraction rings corresponding to (1-11), (111) and (110) indices of monoclinic crystalline structure of $\mathrm{ZrO}_{2}$ nanoparticle [10]. 


\section{UV-Vis spectroscopic analysis}

Figure 8(a) depicts the UV-Visible absorption spectra of $\mathrm{ZrO}_{2}$ nanoparticles synthesized from $0.05 \mathrm{M} \quad(\mathrm{Z} 1)$ and $0.1 \mathrm{M} \quad(\mathrm{Z} 2) \quad \mathrm{ZrOCl}_{2} .8 \mathrm{H}_{2} \mathrm{O}$, respectively which shows strong absorption at 360 $\mathrm{nm}$ and $355 \mathrm{~nm}$ that are shifted from the bulk $\mathrm{ZrO}_{2}$. This phenomenon is associated with charge transfer reaction for monoclinic phase arising from quantum confinement effect of the nanoparticle.

The determination of the optical band gap is obtained by Tauc's equation [18],

$$
\left.(\alpha h v)=A\left(h v-E_{g}\right)\right)^{n}
$$

where, $\mathrm{A}$ is the constant, $\mathrm{h} v$ is photon energy, $\mathrm{Eg}$ is the allowed energy gap, $n=1 / 2$ for allowed direct transition and $\mathrm{n}=2$ for allowed indirect transition; $\alpha$ is the absorption coefficient.

Here

$$
\alpha=\frac{2.303 \times \mathrm{A}}{\mathrm{t}}
$$

where, $\mathrm{A}$ is the absorbance and $\mathrm{t}$ is the thickness of the sample.

$$
\begin{aligned}
& \text { Similarly } \\
& \mathrm{hv}=\frac{1240}{\text { wavelength }(\mathrm{nm})} .
\end{aligned}
$$

The band gap was calculated by extrapolating the curve drawn between (hv) vs $(\alpha h v)^{2}$ to the $\mathrm{x}$-axis as shown in Figure 6(b) and are found to be 3.24 $\mathrm{eV}$ and $3.20 \mathrm{eV}$ for two samples synthesized from $0.05 \mathrm{M} \quad(\mathrm{Z} 1)$ and $0.1 \mathrm{M}$ (Z2) $\mathrm{ZrOCl}_{2} .8 \mathrm{H}_{2} \mathrm{O}$, respectively. Hence, band gap decreases as the concentration of the zirconium precursor increases from $0.05 \mathrm{M}$ to $0.1 \mathrm{M}$, which follows similar trend as reported in $[18,19]$. The variation of particle size and band gap with concentration of zirconium precursor is shown in Figure 9.

\section{Raman study}

The Raman spectrum of zirconia $\left(\mathrm{ZrO}_{2}\right)$ nanoparticle synthesized from $0.05 \mathrm{M} \mathrm{ZrOCl}_{2} .8 \mathrm{H}_{2} \mathrm{O}$ is given in Figure 10, which shows a total of 18 vibrations modes corresponding to the monoclinic phase, out of which only 15 are reported by various researchers [20]. Most of the Raman lines were easily observable for both $\mathrm{A}_{\mathrm{g}}$ and $\mathrm{B}_{\mathrm{g}}$ conditions, but only one of the Raman signals $\left(178 \mathrm{~cm}^{-1}\right)$ has been interpreted as an $\mathrm{A}_{\mathrm{g}}+\mathrm{B}_{\mathrm{g}}$ superposition. The active peaks were observed at 178, 332, 381, 474, 558, and $636 \mathrm{~cm}^{-1}$ in Raman spectra, which belong to the monoclinic phase of zirconium [1]. The peaks at $332 \mathrm{~cm}^{-1}$ and $636 \mathrm{~cm}^{-1}$ are assigned to $A_{g}$ mode. The peaks at $381 \mathrm{~cm}^{-1}$ and $612 \mathrm{~cm}^{-1}$ could be corresponding to the $\mathrm{B}_{\mathrm{g}}$ mode. The remaining peak at $178 \mathrm{~cm}^{-1}$ could be identified as the $\mathrm{A}_{\mathrm{g}}+\mathrm{B}_{\mathrm{g}}$ mode of monoclinic $\mathrm{ZrO}_{2}$ phase. The exhibited bands are clearly indicating that the prepared zirconia sample possessed dominant monoclinic phase of $\mathrm{ZrO}_{2}$. All of the peaks are assigned to $(\mathrm{O}-\mathrm{O}),(\mathrm{Zr}-\mathrm{O})$ and $(\mathrm{Zr}-$ $\mathrm{Zr}$ ) phonon vibration modes [20].

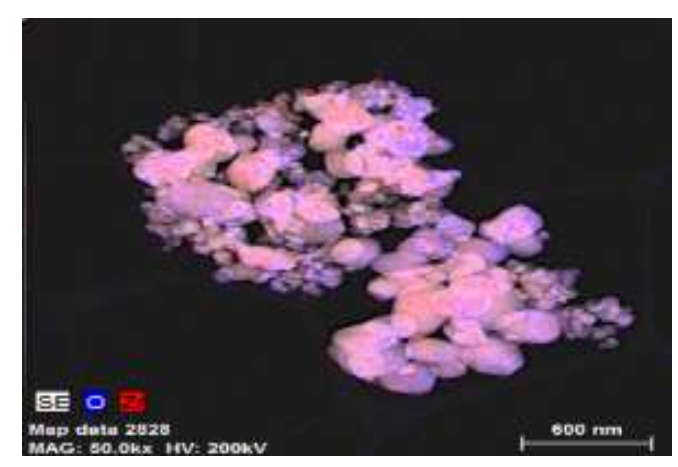

(a)

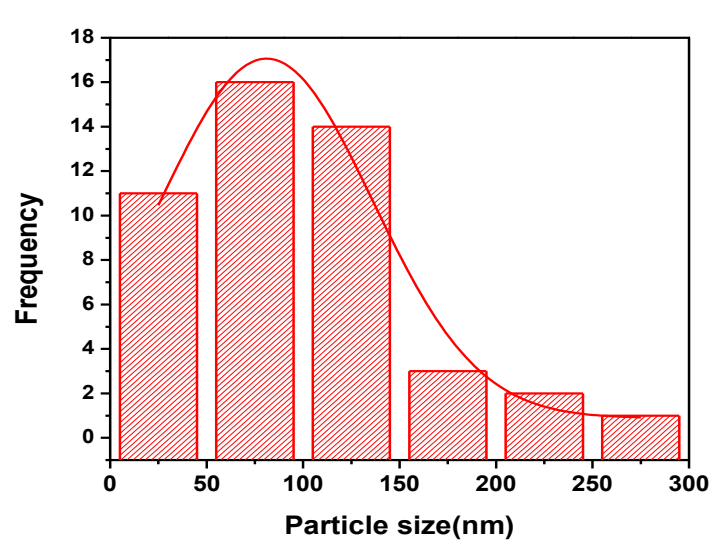

(b)

Fig. 6: (a) TEM image of zirconia nanoparticle using $\quad 0.05 \mathrm{M} \quad \mathrm{ZrOCl}_{2} .8 \mathrm{H}_{2} \mathrm{O} \quad(\mathrm{Z} 1)$ and (b) corresponding histogram. 


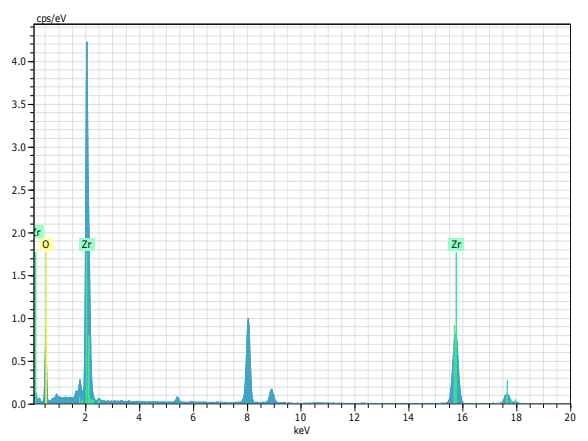

(a)

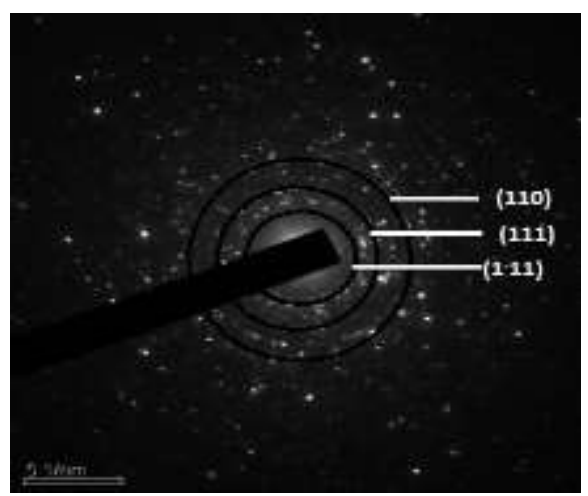

(b)

Fig. 7: (a) TEM-EDX spectra and (b) SAED pattern of zirconia nanoparticle using $0.05 \mathrm{M}$ $\mathrm{ZrOCl}_{2} .8 \mathrm{H}_{2} \mathrm{O}$.

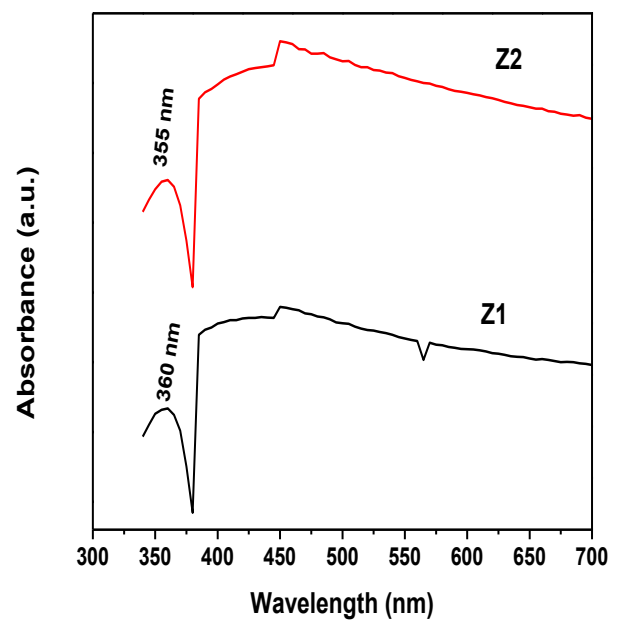

(a)

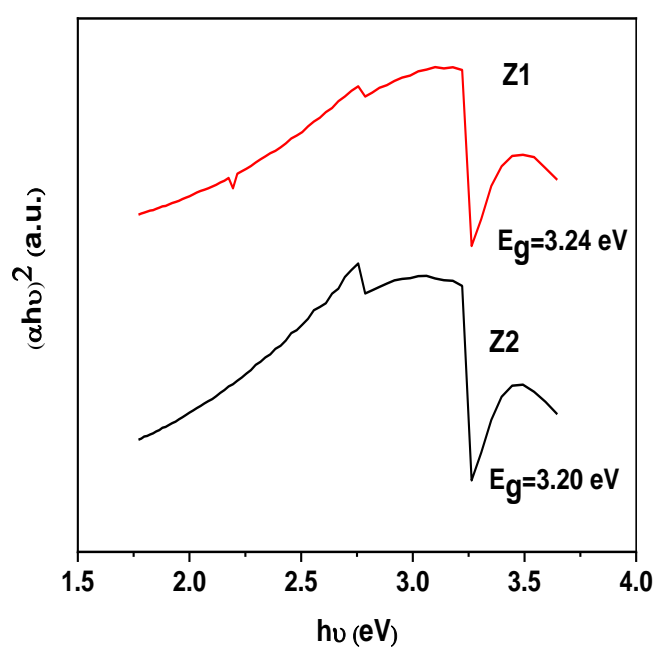

(b)

Fig. 8: (a)UV-Visible absorptions spectra of $\mathrm{ZrO}_{2}$ nanomaterial synthesized from $0.05 \mathrm{M}$ and $0.1 \mathrm{M}$ $\mathrm{ZrOCl}_{2} .8 \mathrm{H}_{2} \mathrm{O} \&$ (b) Corresponding plot of $(\mathrm{h} \mu)$ vs $(\alpha h \mu)^{2}$.

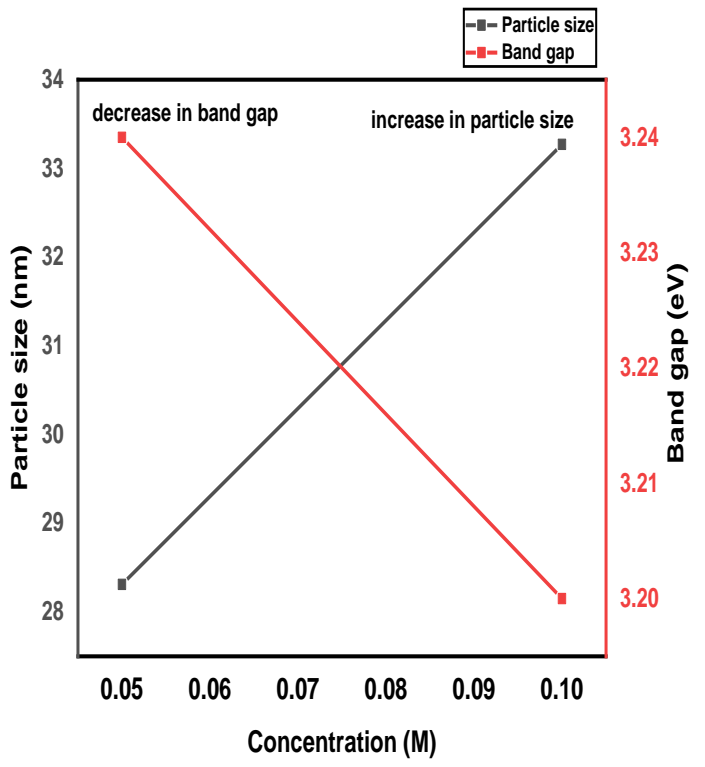

Fig. 9: Variation of particle size and band gap with concentration of zirconium precursor. 


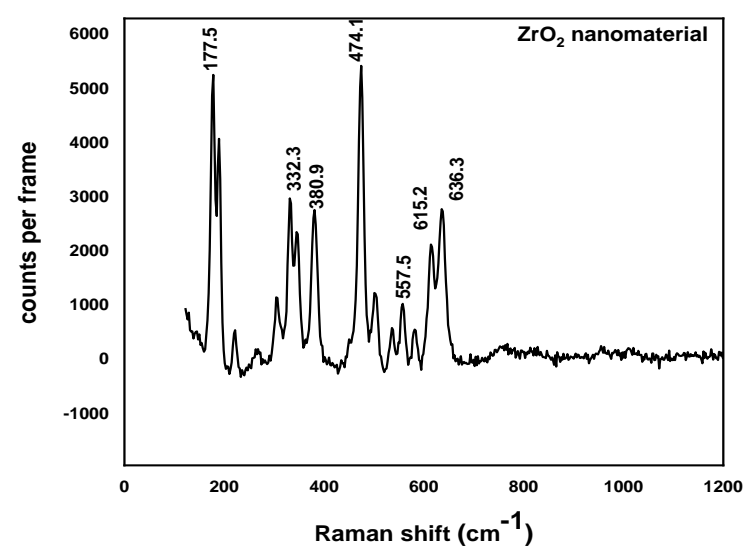

Fig. 10: Raman spectra of $\mathrm{ZrO}_{2}$ nanomaterial synthesized from $0.05 \mathrm{M} \mathrm{ZrOCl} 2.8 \mathrm{H}_{2} \mathrm{O}$.

\section{Conclusions}

Zirconia $\left(\mathrm{ZrO}_{2}\right)$ nanoparticles have been successfully synthesized at two different concentrations $(0.05 \mathrm{M}$ and $0.1 \mathrm{M})$ of zirconium precursor $\left(\mathrm{ZrOCl}_{2} .8 \mathrm{H}_{2} \mathrm{O}\right)$ by co-precipitation method using $\mathrm{NaOH}$ as reducing agent. Pure monoclinic phase was confirmed from XRD result, which is further ensured via Raman spectra and SAED pattern. The average size of nanoparticles increases from $28.3 \mathrm{~nm}$ to $33.3 \mathrm{~nm}$ with increase in the concentration of the solution from $0.05 \mathrm{M}$ to $0.1 \mathrm{M}$. Further, the presence of $\mathrm{Zr}$ and $\mathrm{O}$ species was confirmed via FTIR and EDX analyses. The SEM micrograph and TEM analyses showed well dispersed spherical morphology of the sample with presence of agglomeration. The band gap value is found to decrease from $3.24 \mathrm{eV}$ to $3.20 \mathrm{eV}$ as the particle size increases with increase in the concentration of solution from $0.05 \mathrm{M}$ to $0.1 \mathrm{M}$.

\section{Acknowledgements}

This article is self-sponsored project. The authors' appreciation is extended to Department of Chemistry, Tri-Chandra Campus, Tribhuvan University for providing necessary materials and laboratory for experiments. Authors are thankful to
Ms. Indira Pokhrel, Sogang University, South Korea for SEM and TEM images; Central Department of Chemistry, Tribhuvan University for FTIR characterization and Department of Physics, Tri-Chandra Campus for Raman characterization. Authors also express gratitude to Dr. Satendra P. Singh, Sejong University, South Korea for XRD characterization and helpful discussion.

\section{References}

[1] M. Ramachandran, R. Subadevi, W. R. Liu, M. Siakumari, Facile synthesis and characterization of $\mathrm{ZrO}_{2}$ nanoparticles via modified coprecipitation method, J. Nanoscience and Nanotechnology. 18 (2018) 368-373. http://doi.org/10.1166/jnn.2018.14562.

[2] R. A. Sigwadi, S. E. Mavundla, N. Moloto, T. Mokrani, Synthesis of zirconia-based solid acid nanoparticles for fuel cell application, J. Energy in Southern Africa. 27(2) (2016) 60-67.

[3] V. Thakare, Progress in synthesis and application of zirconia, Int. J. Engineering Research and Development. 5(1) (2012) 25-28.

[4] A. Behbahani, S. Rowshanzamir, A. Esmaeilifar, Hydrothermal synthesis of zirconia nanoparticles from commercial zirconia, Procedia Engineering. 42 (2012) 908-917. http://doi.org/10.1016/j.proeng.2012.07.483.

[5] A. P. Ayanwale, A. D. Cornejo, J. C. C. Gonzalez, L. F. E. Cristobal, S. Y. R. Lopez, Review of the synthesis, characterization and application of zirconia mixed metal oxide nanopartilces, Int. J. Research-Granthalaya. 6(8) (2018) 16-145. http://doi.org/10.5281/zenodo.1403844.

[6] R. Srivastava, Synthesis and characterization techniques of nanomaterials, Int. J. Green Nanotechnology. 4 (2012) 17-27. http://doi.org/10.1080/19430892.2012.654738.

[7] S. L. Jangra, K. Stalin, N. Dilbaghi, S. Kumar, J. Tawale, S. P. Singh, R. Pasricha, Antimicrobial activity of Zirconia $\left(\mathrm{ZrO}_{2}\right)$ nanoparticles and zirconium complex, J. Nanoscience and Nanotechnology. 12 (2012) 7105-7112. http://doi.org/10.1166/jnn.2012.6574.

[8] A. Esmaeilifar, S. Rowshanzamir, A. Behbahani, Hydrothermal synthesis of nano-size zirconia using commercial zirconia powder: process optimization through response surface methodology, Iranian J. Hydrogen \& Fuel Cell. 3 (2014) 163-173.

http://dx.doi.org/10.22104/ijhfc.2017.97. 
[9] A. Mahshad, A. R. Morad, B. Lida, Preparation of high surfaces area $\mathrm{ZrO}_{2}$ nanoparticles, Iran. J. Chem. Eng. 33(2) (2014) 47-53.

[10] K. Geethalakshmi, T. Prabhakaran, J. Hemalatha,Dielectric studies on nano zirconium dioxide synthesized through coprecipitation process, World Academy of Science, Engineering and Technology Int. J. Materials and Metallurgical Engineering. 6(4) 2012 256-259. http://scholar.waste.org/1307-6892/7811.

[11] A. Regmi, J. Bhandari, S. Bhattarai, S. K. Gautam, Synthesis, characterization and antimicrobial activity of cuprous oxide nanoparticles, J. Nepal Chemical Society. 40 (2019) 5-10. https://doi.org:10.3126/jncs.v40i0.27271.

[12] S. Dhungana, B. R. Poudel, S. K. Gautam, Synthesis and characterization of ZnTe nanoparticles, Nepal J. Sci. Tech. 17(1) (2016) 13.

[13] T. Maridurai, D. Balaji, S. Sagadevan, Synthesis and characterization of yttrium stabilized zirconia nanoparticles, Material Research. 19(4) 2016 812816. http://dx.doi.org/10.1590/1982-5373-MR2016-0196.

[14] M. Negahdary, A. H. Tamijani, A. Asadi, S. Ayati, Synthesis of zirconia nanoparticles and their ameliorative roles as additives concrete structures, J. Chemistry. 2013 (2012) 1-7. http://dx.doi.org/10.1155/2013/314862.

[15] S. Gowri, R. R. Gandhi, M. Sundrarajan, Structural, optical, antibacterial and antifungal properties of zirconia nanoparticles by biobased protocol, J. Mater. Sci. Technology. 30(8) (2014) 782-790.

http://dx.doi.org/10.1016/j.jmst.2014.0.002.

[16] S. N. Basahel, T. T. Ali, M. Mokhtar, K. Narasimharao, Influence of crystal structure of nanosized $\mathrm{ZrO}_{2}$ on photocatalytic degradation of methyl orange, Nanoscale Research Letters. 10 (2015) 73-86. http://doi.org/10.1186/s11671-015-0780-z.

[17] M. R. H. Siddiqui, A. I. Al-Wassil, A. M. AlOtaibi, R. M. Mahfouz, Effects of precursor on the morphology and size of $\mathrm{ZrO}_{2}$ nanoparticles, synthesized by sol-gel method in non-aqueous medium, Materials Research. 15(6) (2012) 986989.

http://doi.org/10.1590/S1516143902012005000128.

[18] A. Tumuluri, K. L. Naidu, K. C. J. Raju, Band gap determination using Tauc's plot for $\mathrm{LiNbO}_{3}$ thin flims, Int. J. ChemTech Research. 6(6) (2014) 3353-3356.

[19] S. K. Gautam, D. Pandey, S. N. Upadhyay, S. Anwar, N. P. Lalla, Unambiguous evidence for wurzite phase in capped CdS quantum dots, Solid State Communications. 146 (2008) 425-427. http://doi.org/10.1016/j.ssc.2008.03.020.

[20] Kumari, W. Li, D. Wang, Monoclinic zirconium oxide nanostructures synthesized by a hydrothermal route, Nanotechnology. 19 (2008) 195602-195609.

http://doi.org/10.1088/0957-4454/19/19/195602. 